\title{
Smart Smoking Area based on Fuzzy Decision Tree Algorithm
}

\author{
Iswanto $^{1}$, Kunnu Purwanto ${ }^{2}$, Weni Hastuti ${ }^{3}$, Anis Prabowo ${ }^{4}$, Muhamad Yusvin Mustar ${ }^{5}$ \\ Department of Electrical Engineering, Universitas Muhammadiyah Yogyakarta, Yogyakarta, Indonesia ${ }^{1,2,5}$ \\ Department of D3 Nursing, Institut Teknologi Sains dan Kesehatan PKU Muhammadiyah Surakarta, Surakarta, Indonesia ${ }^{3,4,5}$
}

\begin{abstract}
Cigarette smoke is very dangerous for both active and passive smokers who smoke inside a room because nicotine from cigarette smoke can stick on the wall or in the furniture and produce carcinogenic substances when reacting with air. The carcinogen chemicals in cigarettes are more dangerous when cigarette smoke is trapped in a limited space. An exhaust fan is usually used in a special room for smokers that serves to remove cigarette smoke without exchanging air in it. A smart smoking room tool specifically for smokers was made to answer the problem. The room used an 'in and out' exhaust fan ventilator. This fan ventilator rotated based on the quantity of carbon monoxide (CO) gas in the room detected by using a smoke sensor. Arduino Uno based on Fuzzy Decision Tree algorithm was used to control of the input voltage level in the fan ventilator. The result showed that by using the tool, the cigarette smoke in the room can be controlled effectively.
\end{abstract}

Keywords-Fuzzy decision tree algorithm; smart smoking room; microcontroller; smoke sensor

\section{INTRODUCTION}

This paper is presented systematically starting from introduction which describes the need for a cleaner room free from cigarette smoke, the relevant researches, the aim of the research and the research limitation. The second session presents the method used in this research. The research result is discussed in the third session and the conclusion of the research is written in the fourth session.

Indonesia is the third country in the world with the highest number of smokers after China and India. Smoking in the room will leave nicotine on home furniture and wall. Nicotine reacts with air and produces carcinogenic substances. The carcinogenic chemicals in cigarettes are more dangerous when cigarette smoke is trapped in a limited space. There is usually an exhaust fan to remove cigarette smoke without circulating the air in and out the smoking room. This makes unhealthy conditions. Keeping the room windows open will not solve the problem. Large amount of cigarette smoke actually stays or returns to the room and continues to stay indoor for hours.

Based on the problem, a tool which is a prototype of a smart room specifically for smoking was made. This room used two ventilators namely exhaust fans to circulate the air in and out the room. These ventilators made the air flow in the room replacing the air and out the room to remove the cigarette smoke so that it would reduce the risk of sticking harmful gases that stick to the walls of the room. These fan ventilators rotated based on the quantity of carbon monoxide (CO) gas in the room. The level of carbon monoxide (CO) in the room will be monitored by the LCD and there was an indicator light as a warning system if the air level in the room reached a dangerous level; controlling the input voltage level of the fan ventilator using Arduino Uno.

Detecting smoke using a microcontroller has been investigated by previous researchers. Smart Home Automation was studied by Islam to control lights, heating water machine, washing machine and doors. The system uses several sensors consisting of flame sensor to detect fire, camera sensor to detect people's movements, DHT11 sensor to detect temperature, and smoke sensor with MQ 3 and MQ135 by using CRIPS algorithm [1]. The fire detection system was examined by Elizalde using temperature sensor, GPS sensor and ionization sensor. Ionization sensor is a sensor that can detect smoke. The three sensors were processed by ATmega328 by using Comparative algorithm sent using the Zigbee and GSM modules [2].

A vehicle accident notification system was investigated by Dias using several sensors processed by Arduino. Those sensors were shock sensor, accelerometer sensor and GPS sensor used for tracking, and smoke sensor and GPS sensor for detecting accidents and providing accident position notifications by using tracking algorithm [3]. Monitoring forest fire was investigated by Fengbo using several sensors including smoke sensor, temperature, humidity, fire, and light sensors connected to CC2530 microcontroller type. The microcontroller was used to process data by using data processing algorithm transferred to the monitoring terminal using Zegbee [4].

A healthy environmental monitoring system for smart cities was examined by Ghosal using a quadrotor. To monitor a healthy environment, several sensors such as LM35 sensor, AM1001 sensor, LDR Sensor, MQ 6 Sensor and MQ135 Sensor connected to Arduino were carried by the quadrotor. The sensors were processed by Arduino ATmega328. The data were then captured by using WiFi [5]. A server space control and monitoring system was investigated by Roihan by using several sensors connected to Wemos microcontroller. The system consisted of Arduino type Wemos, DHT11 sensor to detect humidity and temperature, and MQ2 sensor to detect smoke. The system is equipped with a GSM module so that it can send the data to the internet [6].

A house environmental monitoring system was examined by Mahara Jothi connected with GSM communication. This system consisted of temperature sensor, PIR sensor, ultrasonic sensor, and smoke sensor connected to Arduino. The system 
worked remotely for monitoring and control since it was connected to GSM controlled using a mobile phone [7]. A fire extinguisher robot was designed and examined by Bose using a PIC16F876A type microcontroller. This system consisted of fire sensors including gas sensor and temperature sensor connected to a microcontroller. When the amount of smoke or the temperature increases, this system turns on the fire extinguisher pump [8].

Environmental quality monitoring system was examined by Islam using cloud data logging. To detect air quality, this system used a sensor consisting of CO2, CO, LPG, Smoke, alcohol, benzene, $\mathrm{NH} 3$, temperature and $\mathrm{pH}$ sensors connected to Arduino Uno. The data from Arduino Uno were processed by using artificial intelligent algorithm and then sent to the cloud server using GPRS [9]. Detection of asthma triggers was investigated by Indulakshmi using the reference air quality index. MQ2 sensor was used in this system to determine the air quality in the environment. MQ2 sensor data were read and processed by the nodeMCU type microcontroller by using comparative algorithm and then transmitted to the network using cloud servers from Adafruit [10].

The alarm system to determine the location of the accident was examined by the Desima using smoke sensor, fire sensor and switches. The smoke sensor uses MQ135 to detect gas carbon dioxide (CO2) fumes. The sensors were the Arduino Uno microcontroller inputs then they were processed to be transmitted using the GSM module [11]. The vehicle accident tracking system was investigated by John using alcohol sensor, eye sensor, and smoke sensor. The system used an ATmega328 microcontroller to read the alcohol sensor, eye sensor, pizzo-electric vibration sensor, smoke sensor and tilt sensor. The data processed by the microcontroller were transmitted using a GSM module [12].

Portable systems for transmitting and accounting data were examined by Yordanov. This acquisition data were used for sensor data such as humidity, air pollution gas, dust and smoke. These transmission data send the data using Bluetooth and GPRS or GSM. PIC type microcontrollers were needed to process sensor data [13]. Environmental monitoring in the factory area for employee safety was examined by Kodali. The system used three sensors namely temperature sensor, smoke sensor, and ultrasonic sensor. MTQQ algorithm was applied to Arduino NodeMCU type microcontroller used to process sensor data and sends the data to the internet using Wi Fi [14].

Many previous researchers have conducted researches on smoke sensors. The smoke sensors have been used for smart home systems, fire detection systems, vehicle accident notification systems, forest fire monitoring systems, healthy environmental monitoring systems, fire-fighting robots, asthma trigger detection systems and many others. The methods used by the previous researchers are Comparative algorithm and smart control methods such as MTQQ algorithm, artificial intelligent, and data processing algorithm. The author uses fuzzy decision tree method.
This paper presents MQ2 and MQ7 smoke sensors to make a smart smoking area system. This system uses two exhaust fans to suck in and blow the smoke out the room. The research is limited for a small room.

\section{RESEARCH METHOD}

Two methods for a smart smoking area were presented namely block diagram design method and algorithmic method. Fig. 1 shows the smart smoking area design. It can be seen that the system consists of input system, output system and control system. The input system uses smoke sensors to detect cigarette smoke. This input system uses MQ-2 and MQ-7 gas sensors to detect and read carbon monoxide gas as the result of burning cigarettes. The data are processed by the control system using Arduino uno [15]. The output system consists of an exhaust fan for sucking the air, an exhaust fan for blowing the air, and an LCD display [16], [17].

An algorithm fuzzy decision tree [18]-[20] method for a smart smoking area is shown by a flowchart decision tree in Fig. 2. The chart shows that the smoke sensor uses I2C communication. The MQ2 and MQ7 sensor data are processed using fuzzy algorithm by comparing sensor data with set points. When the smoke is above than 200, the red LED light is on and the fan is on. When the smoke is less than 200, the blue LED light is on, and the fan is off.

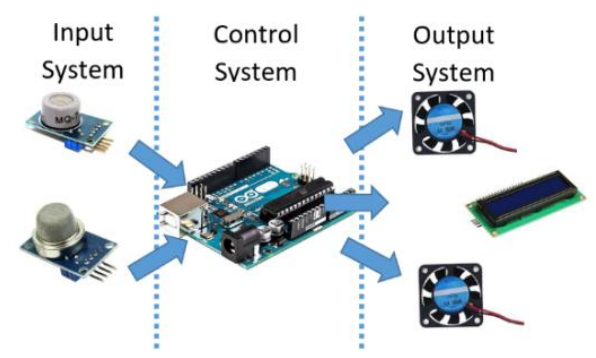

Fig. 1. Block Diagram of a Smart Smoking Area System.

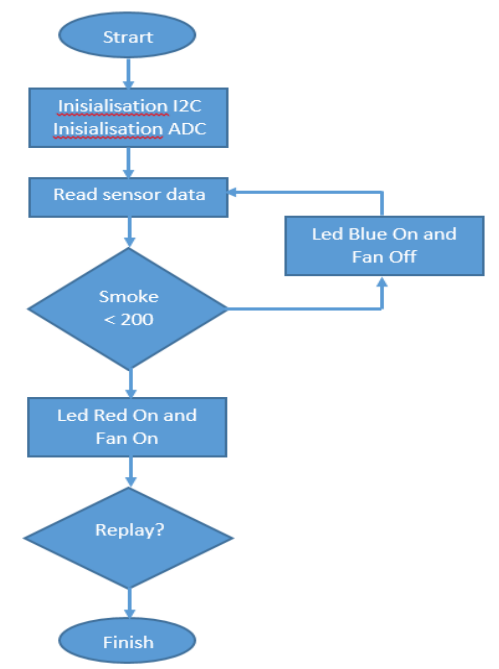

Fig. 2. Flowchart of a Smart Smoking Area. 


\section{DISCUSSION}

Testing the smart smoking area using Arduino with the MQ7 and MQ2 sensors was carried out on a prototype with size of $38 \times 29 \times 21$. In the prototype, there were MQ7 and MQ2 gas sensors to detect $\mathrm{CO}$ gas levels in the box. The prototype was connected to a controller circuit served to adjust the $\mathrm{AC}$ in the fan in and fan out.

Fig. 3 shows the smart smoking-room system. The tests on MQ2 and MQ7 sensors were performed by connecting the MQ2 and MQ7 sensors to the Arduino Uno module and to the laptop to upload the program in the Arduino Uno module to check the MQ7 and MQ2 Sensors. The sensor works in accordance to the desired input. Table I is the result of MQ7 gas sensor voltage test at every 5 second increase.

Referring to the table, there is a slight difference in MQ7 gas sensor voltage test in the Arduino IDE monitor series with a measured multi-meter in comparison with an average difference of 0.0081 . This proved that the sensor works as it should. There was an error at the time of measurement with an average error of 0.001228641 or $0 \%$.

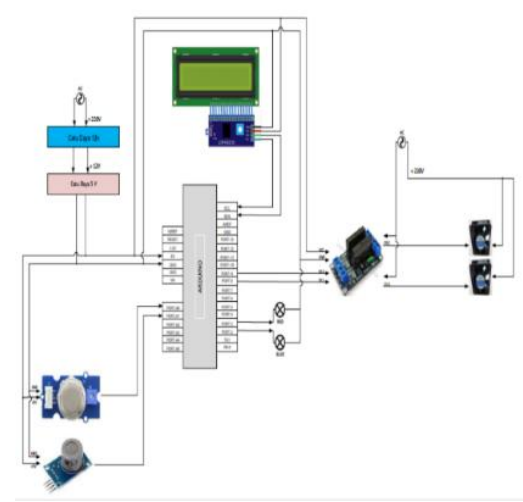

Fig. 3. Smart Smoking Room System.

TABLE I. Result of THE MQ7 Gas Sensor Voltage Test

\begin{tabular}{|l|l|l|l|l|l|}
\hline No & $\begin{array}{l}\text { Time } \\
(\mathrm{s})\end{array}$ & $\begin{array}{l}\text { Monitor } \\
\text { series } \\
\text { voltage } \\
\text { (volt) }\end{array}$ & $\begin{array}{l}\text { Multimeter } \\
\text { voltage (volt) }\end{array}$ & $\begin{array}{l}\text { Error } \\
\text { (error) }\end{array}$ & $\begin{array}{l}\text { Percentage } \\
(\%)\end{array}$ \\
\hline 1 & 5 & 0.69 & 0.701 & 0.0006 & $0 \%$ \\
\hline 2 & 10 & 0.7 & 0.691 & 0.0006 & $0 \%$ \\
\hline 3 & 15 & 1.06 & 1.049 & 0.0010 & $0 \%$ \\
\hline 4 & 20 & 1.22 & 1.215 & 0.0011 & $0 \%$ \\
\hline 5 & 25 & 1.3 & 1.291 & 0.0012 & $0 \%$ \\
\hline 6 & 30 & 1.33 & 1.299 & 0.0012 & $0 \%$ \\
\hline 7 & 35 & 1.36 & 1.401 & 0.0013 & $0 \%$ \\
\hline 8 & 40 & 1.55 & 1.547 & 0.0015 & $0 \%$ \\
\hline 9 & 45 & 1.56 & 1.556 & 0.0015 & $0 \%$ \\
\hline 10 & 50 & 1.88 & 1.819 & 0.0017 & $0 \%$ \\
\hline Sum & & 0.081 & 0.0122 & $0 \%$ \\
\hline Average & & 0.0081 & 0.0012 & $0 \%$ \\
\hline
\end{tabular}

\begin{tabular}{|l|l|l|l|l|l|}
\hline No & $\begin{array}{l}\text { Time } \\
(s)\end{array}$ & $\begin{array}{l}\text { Monitor } \\
\text { series } \\
\text { voltage } \\
\text { (volt) }\end{array}$ & $\begin{array}{l}\text { Multimeter } \\
\text { voltage (volt) }\end{array}$ & $\begin{array}{l}\text { Error } \\
\text { (error) }\end{array}$ & $\begin{array}{l}\text { Percentage } \\
(\%)\end{array}$ \\
\hline 1 & 5 & 0.73 & 0.726 & 0.0007 & $0 \%$ \\
\hline 2 & 10 & 0.74 & 0.729 & 0.0007 & $0 \%$ \\
\hline 3 & 15 & 1.33 & 1.299 & 0.0012 & $0 \%$ \\
\hline 4 & 20 & 1.39 & 1.401 & 0.0013 & $0 \%$ \\
\hline 5 & 25 & 139 & 1.401 & 0.0013 & $0 \%$ \\
\hline 6 & 30 & 1.41 & 1.409 & 0.0013 & $0 \%$ \\
\hline 7 & 35 & 1.42 & 1.399 & 0.0013 & $0 \%$ \\
\hline 8 & 40 & 1.44 & 1.427 & 0.0013 & $0 \%$ \\
\hline 9 & 45 & 1.55 & 1.502 & 0.0014 & $0 \%$ \\
\hline 10 & 50 & 1.88 & 1.798 & 0.0017 & $0 \%$ \\
\hline Sum & & & & 0.0127 & $0 \%$ \\
\hline Average & & & 0.0012 & $0 \%$ \\
\hline
\end{tabular}

Fig. 4 shows MQ7 sensor voltage test graph. It can be seen in the figure that the ratio between LCD voltage and the multimeter voltage is getting higher, due to the sensor heating. The hotter the sensor the higher is the voltage. Table II is the result of MQ2 gas sensor voltage test at every 5 second increase.

There is a similarity between the MQ7 gas measurement and the voltage measurement that is the voltage measured by the multi-meter and the voltage measured in the Arduino IDE serial monitor shows a slight difference. This proves that the sensor works as it should. The average error is 0.001279668 or $0 \%$.

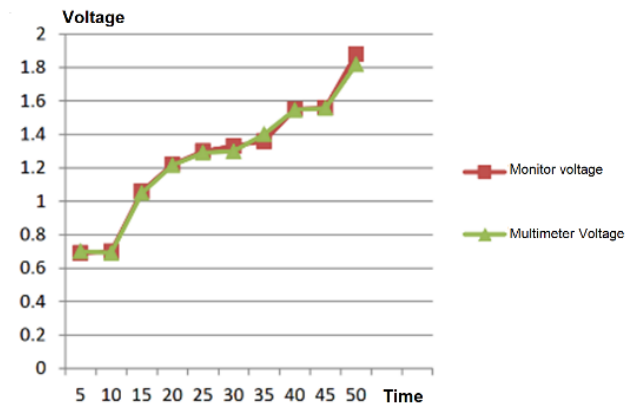

Fig. 4. MQ7 Sensor Voltage Test.

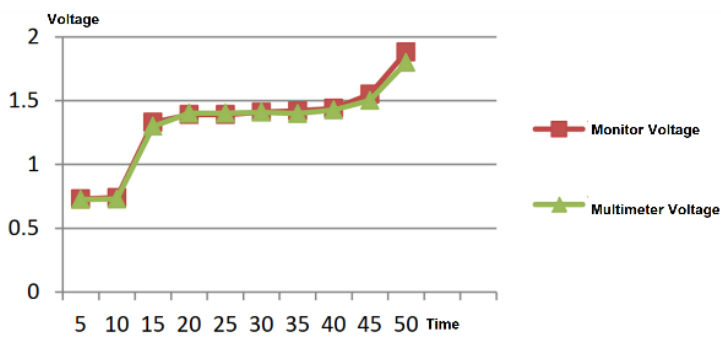

Fig. 5. MQ2 Sensor Voltage Test.

TABLE II. MQ2 Gas Sensor Voltage Test Sensor 
Table III is the test on the characteristics of the MQ2 sensor was performed by testing the output voltage when the chimney is closed for 3 minutes 20 seconds as shown in Fig. 5. The figure shows that the tests were carried out every 20 seconds increasing from 20 seconds to 160 seconds using a multi-meter.

The table shows that the voltage decreases every 20 second increase. This proves that the less smoke is in the room, the lower the voltage will be and vice versa.

As illustrated in Fig. 6, it can be seen in the graph that the more smoke in the room, the higher the voltage produced. Afterward, when the fan is active, the smoke will decrease and so will the voltage. Table IV is the test on the characteristics of the MQ7 sensor was performed by testing the output voltage when the chimney is closed for 3 minutes 20 seconds. The tests were carried out every 20 seconds increasing from 20 seconds to 160 seconds using a multi-meter.

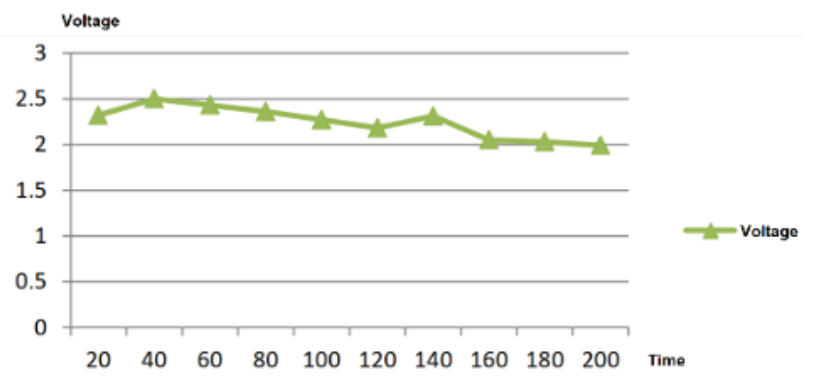

Fig. 6. Results of MQ2 Gas Characteristics Test.

TABLE III. Results of MQ2 Gas SEnsor Characteristics Test

\begin{tabular}{|l|l|l|}
\hline No & Time (second) & Voltage (volt) \\
\hline 1. & 20 & 2,32 volt \\
\hline 2. & 40 & 2,50 volt \\
\hline 3. & 60 & 2,43 volt \\
\hline 4. & 80 & 2,36 volt \\
\hline 5. & 100 & 2,27 volt \\
\hline 6. & 120 & 2,18 volt \\
\hline 7. & 140 & 2,31 volt \\
\hline 8. & 160 & 2,05 volt \\
\hline
\end{tabular}

TABLE IV. Results of MQ7 GAS SENSOR Characteristics TeST

\begin{tabular}{|l|l|l|}
\hline No & Time (second) & Voltage (volt) \\
\hline 1. & 20 & 2,32 volt \\
\hline 2. & 40 & 2,50 volt \\
\hline 3. & 60 & 2,43 volt \\
\hline 4. & 80 & 2,36 volt \\
\hline 5. & 100 & 2.46 \\
\hline 6. & 120 & 2.41 \\
\hline 7. & 140 & 2.4 \\
\hline 8. & 160 & 2.35 \\
\hline
\end{tabular}

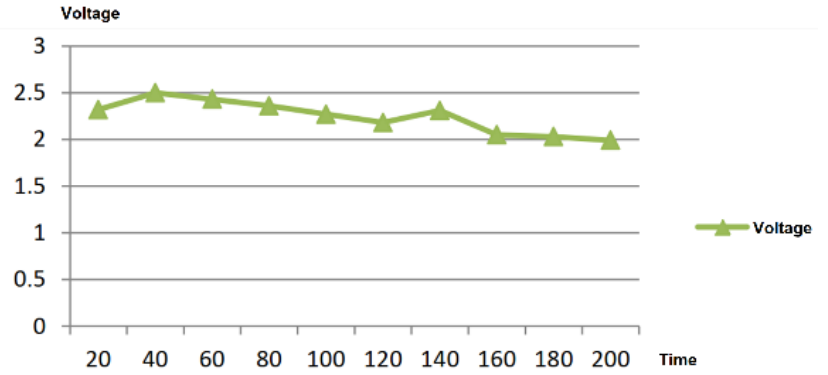

Fig. 7. Results of MQ2 Gas Characteristics Test.

The table shows that the more $\mathrm{CO}$ gas content in a room, the higher the voltage. Afterward, when the fan is active the voltage will decrease due to the decrease of the $\mathrm{CO}$ gas.

Fig. 7 shows the same characteristic of gas sensor in that the higher voltage is generated from the higher $\mathrm{CO}$ gas content in the room. Similar to the previous graph, the greater the gas content in the room, the higher the voltage produced.

\section{CONCLUSION}

Based on the results of testing and discussion, it can be concluded that a smart smoking area system has been realized. The system can detect cigarette smoke in the room. When the cigarette smoke in the room increases, the DC motor moves the fan to circulate cigarette smoke out and in the room. The room is clean of smoke because the air inside the room is sucked out and the fresh air from outside is sucked in the room. Therefore, the room will always contain fresh air. From the smokers' point of view, this smart smoking room can help them to feel more comfortable because there is no cigarette smoke that causes cough and eyes. It is expected that an algorithm or technology is added for larger smart smoking rooms.

\section{REFERENCES}

[1] A. Islam, "Android Application Based Smart Home Automation System Using Internet of Things," in 2018 3rd International Conference for Convergence in Technology (I2CT), 2018, pp. 1-9.

[2] D. Q. R. Elizalde, R. J. P. Garcia, M. M. S. Mitra, and R. G. Maramba, "Wireless Automated Fire Detection System on Utility Posts Using ATmega328P," in 2018 IEEE 10th International Conference on Humanoid, Nanotechnology, Information Technology,Communication and Control, Environment and Management (HNICEM), 2018, pp. 1-5.

[3] R. Dias, V. Ghike, J. Johnraj, N. Fernandes, and A. Jadhav, "Vehicle Tracking and Accident Notification System," in 2018 3rd International Conference for Convergence in Technology (I2CT), 2018, pp. 1-4.

[4] W. Fengbo, L. Xitong, and Z. Huike, "Design and Development of Forest Fire Monitoring Terminal," in 2018 International Conference on Sensor Networks and Signal Processing (SNSP), 2018, pp. 40-44.

[5] M. Ghosal, A. Bobade, and P. Verma, "A Quadcopter Based Environment Health Monitoring System for Smart Cities," in 2018 2nd International Conference on Trends in Electronics and Informatics (ICOEI), 2018, pp. 1423-1426.

[6] A. Roihan, F. Sudarto, and T. Cahyo Putro, "Internet of Things on Monitoring and Control System in Server Area," in 2018 International Seminar on Application for Technology of Information and Communication, 2018, pp. 116-120.

[7] T. Mahara Jothi, A. Periyanayaki, R. Srimathy, M. Vinotha, and G. Gopika, "GSM Based Home Environment Monitoring System," in 2018 2nd International Conference on Trends in Electronics and Informatics (ICOEI), 2018, no. Icoei, pp. 1263-1268. 
[8] J. S. C. Bose, M. Mehrez, A. S. Badawy, W. Ghribi, H. Bangali, and A. Basha, "Development and designing of fire fighter robotics using cyber security," in 2017 2nd International Conference on Anti-Cyber Crimes (ICACC), 2017, pp. 118-122.

[9] M. S. Islam, "An Intelligent System on Environment Quality Remote Monitoring and Cloud Data Logging Using Internet of Things (IoT)," in 2018 International Conference on Computer, Communication, Chemical, Material and Electronic Engineering (IC4ME2), 2018, pp. 14.

[10] S. Indulakshmi, M. Adithya, A. R. Anirudh, and A. Jawahar, "Design and Development of Prototype Model for Asthma Trigger Detection," in 2018 International Conference on Wireless Communications, Signal Processing and Networking (WiSPNET), 2018, pp. 1-5.

[11] M. A. Desima, P. Ramli, D. F. Ramdani, and S. Rahman, "Alarm system to detect the location of IOT-based public vehicle accidents," in 2017 International Conference on Computing, Engineering, and Design (ICCED), 2017, pp. 1-5.

[12] A. John and P. R. Nishanth, "Real time embedded system for accident prevention," in 2017 International conference of Electronics, Communication and Aerospace Technology (ICECA), 2017, pp. 645648.

[13] R. Yordanov, R. Miletiev, P. Kapanakov, and E. Lontchev, "Design of a portable system for sensor data acquisition and transmission," in 2017 XXVI International Scientific Conference Electronics (ET), 2017, pp. 13.
[14] R. K. Kodali and A. Valdas, "MQTT based environment monitoring in factories for employee safety," in 2017 3rd International Conference on Applied and Theoretical Computing and Communication Technology (iCATccT), 2017, pp. 152-155.

[15] K. Purwanto, I. -, T. Khristanto, and M. Yusvin, "Microcontroller-based RFID, GSM and GPS for Motorcycle Security System," Int. J. Adv. Comput. Sci. Appl., vol. 10, no. 3, pp. 447-451, 2019.

[16] A. N. N. Chamim, M. H. Gustaman, N. M. Raharja, and Iswanto, "Uninterruptable power supply based on switching regulator and modified sine wave," Int. J. Electr. Comput. Eng., vol. 7, no. 3, pp. 1161-1170, 2017.

[17] A. N. N. Chamim, D. Ahmadi, and Iswanto, "Atmega16 implementation as indicators of maximum speed," Int. J. Appl. Eng. Res., vol. 11, no. 15, pp. 8432-8435, 2016.

[18] T. P. Tunggal, A. Supriyanto, R. Nur Mukhammad Zaidatur, I. Faishal, I. Pambudi, and T. Iswanto, "Pursuit algorithm for robot trash can based on fuzzy-cell decomposition," Int. J. Electr. Comput. Eng., vol. 6, no. 6, pp. 2863-2869, 2016.

[19] Iswanto, O. Wahyunggoro, and A. I. Cahyadi, "Path planning based on fuzzy decision trees and potential field," Int. J. Electr. Comput. Eng., vol. 6, no. 1, pp. 212-222, 2016.

[20] I. Iswanto, O. Wahyunggoro, and A. I. Cahyadi, "Formation Pattern Based on Modified Cell Decomposition Algorithm," Int. J. Adv. Sci. Eng. Inf. Technol., vol. 7, no. 3, p. 829, Jun. 2017. 